\title{
REGISTROS NA RESOLUÇÃO DE MULTIPLICAÇÕES E DIVISÕES: DESVELANDO A PRODUÇÃO DE ALUNOS DO 4\% ANO
}

\section{REGISTERS AT SOLVING MULTIPLICATIONS AND DIVISIONS: UNVEILING THE PRODUCTION OF 4TH GRADE STUDENTS}

Mariana Aline Nita ${ }^{1}$

ORCID iD: 0000-0002-5176-7151

Sueli Fanizzi ${ }^{2}$

ORCID iD: 0000-0001-6436-8742

Vanessa Lacerda Tarouco ${ }^{3}$

ORCID iD: 0000-0002-5029-4049

\section{RESUMO}

O presente artigo corresponde às reflexões e constatações provenientes de uma das fases da pesquisa intitulada A interação nas aulas de Matemática: da negociação de significados à construção de conhecimentos, realizada no âmbito da Universidade Federal de Mato Grosso, nos anos de 2019 e 2020. $\mathrm{O}$ estudo dessa fase teve por objetivo analisar o registro de alunos ingressantes no $4^{\circ}$ ano do ensino fundamental na resolução das operações de multiplicação e divisão. Os dados foram retirados da avaliação diagnóstica, aplicada pela escola participante da pesquisa, instrumento que orientou o encaminhamento dos alunos com dificuldades em Matemática para a sala de apoio pedagógico. A análise dos registros ocorreu de forma qualitativa, como base no método interpretativo. Conclui-se que existem diversas possibilidades de registro para a expressão do conhecimento acerca da técnica da multiplicação e da divisão que, embora não sejam convencionais, podem revelar significativas relações matemáticas construídas pelos alunos.

Palavras-chave: Multiplicação e divisão. Anos iniciais. Registro. Significado das operações.

\begin{abstract}
The present article corresponds to reflections and evidence coming from one of the steps of the research Interaction in Mathematics classes: from negotiating meanings to building knowledges, which took place in the sphere of the Universidade Federal de Mato Grosso in 2019 and 2020. The objective of studying this stage was to analyze the registers of students entering elementary school 4th grade in solving multiplication and division operations. Data were taken from a diagnostic evaluation applied by the school taking part in the research, a tool that worked as a support to direct Mathematics difficulties

\footnotetext{
${ }^{1}$ Graduanda de Pedagogia pela Universidade Federal de Mato Grosso (UFMT), Cuiabá, Mato Grosso, Brasil. Rua Cardeal, número 552, Quadra 26, Recanto dos Pássaros, Cuiabá-MT, Brasil, 78075-280. E-mail: mari_nita@hotmail.com.

${ }^{2}$ Doutora em Educação pela Faculdade de Educação da Universidade de São Paulo (FEUSP). Professora Adjunta do Instituto de Educação da Universidade Federal de Mato Grosso (IE-UFMT), Cuiabá, MT, Brasil. Av. Fernando Corrêa da Costa, 2367 - Boa Esperança, Cuiabá - MT, 78060-900. E-mail: suelifanizzi@ gmail.com.

${ }^{3}$ Mestre em Educação pela Universidade Federal de Mato Grosso (UFMT). Professora da Rede Municipal de Ensino de Cuiabá, Cuiabá-MT, Brasil. Rua Antônio Dorileo, nº 250, Coophema, Cuiabá-MT, Brasil, 78085-230. E-mail: vanessaltarouco@gmail.com.
} 
students to pedagogical support room. The registers analysis was qualitative and used an interpretative method. The conclusion is: there are many register possibilities for expressing knowledge about multiplication and division that, while unconventional, may reveal significant mathematical relationships made up by students.

Key words: Multiplication and division. First years. Students' registers. Meaning of operations.

\title{
1 INTRODUÇÃO
}

O presente artigo corresponde à apresentação de uma etapa da pesquisa intitulada $A$ interação nas aulas de Matemática: da negociação de significados à construção de conhecimentos, desenvolvida no âmbito das atividades acadêmico-científicas da Universidade Federal de Mato Grosso, e à parte do plano de trabalho do Programa de Iniciação Científica de uma estudante da graduação de Licenciatura em Pedagogia, vinculado à pesquisa. Por negociação de significados, compactuamos com a conceituação de Ponte e Serrazina.

\begin{abstract}
A negociação de significados matemáticos na sala de aula implica que cada um dos intervenientes, professor e alunos, tornem os seus próprios significados visíveis no processo. Através da troca de ideias realizada pela comunicação, cada um fica a conhecer melhor os referentes do outro (PONTE; SERRAZINA, 2000, p. 123).
\end{abstract}

As ações da pesquisa têm como público alvo estudantes do segundo ciclo do ensino fundamental de escolas da Rede Municipal de Ensino de Cuiabá, em particular aqueles que frequentam a sala de apoio pedagógico de Matemática da escola. Na Rede Municipal de Ensino de Cuiabá são ofertadas, ao longo do ano letivo, aulas extras aos alunos diagnosticados com dificuldades de aprendizagem nas áreas de Língua Portuguesa e de Matemática, no contra turno das aulas regulares. O objetivo central da pesquisa é o de propor e analisar formas de interação nas aulas de apoio pedagógico, que possibilitem aos alunos, a negociação de significados e, consequentemente, o enfrentamento e a superação de suas dificuldades em Matemática. Como a pesquisa está em curso e é composta por diferentes etapas até a ocorrência da observação dessas aulas e posterior intervenção por parte de seus membros, para este artigo, foi selecionada a análise da avaliação diagnóstica, aplicada em fevereiro de 2020, nas quatro salas de $4^{\circ}$ ano da segunda escola participante do projeto - um dos instrumentos dos professores regentes para o encaminhamento dos alunos à sala de apoio pedagógico -, com o propósito de compreender o registro dos alunos na resolução da multiplicação e da divisão. Com o advento da pandemia da COVID-19 e da interrupção das aulas presenciais, até o início do segundo semestre de 2020, as aulas de apoio pedagógico da escola ainda não haviam sido iniciadas.

Diante da análise das avaliações dos mais de 100 alunos do $4^{\circ}$ ano e, em especial, de uma questão sobre a resolução de operações de multiplicação e divisão, verificamos que as 
tentativas de solução e os erros cometidos por alunos do $4^{\circ}$ ano oferecem indícios sobre suas estratégias e formas de raciocínio, permitindo que planejemos intervenções condizentes com as diferentes fases de aprendizagem daqueles que podem compor uma sala de apoio pedagógico. Além disso, a partir desse estudo, poderemos oferecer, à coordenação pedagógica da escola, um mapeamento das resoluções de multiplicações e divisões, acompanhado da análise do registro das estratégias empregadas pelos alunos do $4^{\circ}$ ano, que procuraram negociar significados entre o que convencionalmente se determina na aprendizagem da "conta armada", e a compreensão não somente do passo a passo da técnica algorítmica, como também do significado dessas operações matemáticas

O objetivo deste estudo foi o de identificar como alunos no início do $4^{\circ}$ ano resolvem multiplicações e divisões em uma única questão que oferecia espaço para a resposta e, consequentemente, a possibilidade de registro de estratégias de resolução, de um instrumento diagnóstico composto por questões de múltipla escolha em quase sua totalidade. Foram duas as perguntas que guiaram a análise: Que tipo de resposta pode aparecer na resolução de multiplicações e divisões propostas na estrutura horizontal, como $5 \times 9=$ e 46:2=, em um instrumento diagnóstico de alunos recém ingressantes no $4^{\circ}$ ano? Na tentativa de registrar uma estratégia de resolução, quais os percursos adotados pelos alunos? As respostas dos alunos foram díspares, bem como as formas de registro daqueles que apresentaram suas estratégias, o que nos motivou a produzir uma análise mais pormenorizada dos resultados. Os referenciais teóricos que fundamentaram este trabalho fazem parte da bibliografia mais ampla da pesquisa e incluem outros autores que abordam o tema da aprendizagem das operações elementares, em particular, da multiplicação e da divisão, como Vergnaud (2004), que idealizou a Teoria dos Campos Conceituais.

Um dos estudos que nos subsidiou, sobretudo, na etapa da análise dos dados, foi o desenvolvido por Nacarato, Mengali e Passos (2009), no qual as autoras apresentam contextos de sala de aula, com exemplos de registros e enunciações de alunos que ocorreram em um ambiente de aprendizagem pautado no diálogo, nas interações e na negociação de significados.

Assim que foi estabelecido o contato com a coordenadora da escola, no início do ano, soubemos que as operações com números naturais seriam um dos temas do $4^{\circ}$ ano e foco do trabalho inicial da sala de apoio e aprendizagem de Matemática, assim que as aulas começassem. Ainda nos dias de hoje, o trabalho com as operações aritméticas fundamentais, em geral, é enfatizado nas aulas de Matemática dos anos iniciais de escolaridade, apesar da existência de outras unidades temáticas presentes nas atuais orientações da Base Nacional Comum Curricular (BRASIL, 2017). 
O registro - ou não registro - do aluno para a resolução de multiplicações e divisões aponta para a compreensão dos sentidos que ele atribui a essas operações e para a importância de "o professor organizar melhor seu ensino a fim de criar situações apropriadas para o aluno superar seus erros e apropriar-se dos conhecimentos necessários à sua cidadania" (PINTO, 2000, p. 11). Dessa forma, em consonância com as ideias da autora (PINTO, 2000), vale destacar que o erro foi concebido, neste trabalho, como um estágio provisório da aprendizagem e pode ser analisado no sentido de subsidiar a prática docente e promover a aprendizagem.

A seguir, discorreremos sobre dois aspectos concernentes à compreensão dos alunos acerca das operações aritméticas fundamentais, a saber: (a) a expressão de ideias matemáticas para além das regras convencionais e (b) a compreensão dos significados das operações aritméticas fundamentais e a teoria dos campos conceituais.

\section{REFERENCIAL TEÓRICO}

\subsection{A expressão de ideias matemáticas para além das regras convencionais}

Nos anos iniciais de escolaridade, a língua materna e suas possibilidades de expressão apoiam a aprendizagem da Matemática, na medida em que os alunos encontram meios de comunicar a construção de conhecimentos matemáticos com registros orais e escritos, que vão além dos símbolos e técnicas próprios da área. O uso da linguagem oral, estimulada em momentos de interação nas aulas de Matemática, ou o emprego, por exemplo, de um desenho para a resolução de uma situação-problema são caminhos de os alunos atribuírem sentido à tão temida matemática escolar, que merecem a devida atenção por parte do professor.

Referindo-se ao conhecimento matemático, Gómez-Granell (1997, p. 21) afirma:

[...] no processo de ensino e aprendizagem desse conhecimento formal, os processos
intuitivos próprios do pensamento cotidiano desempenham um papel constitutivo
essencial, assim como ocorre no processo de construção científica. Se forem deixados
de lado, corre-se o risco de transmitir, como vem sucedendo na escola atualmente, um
conhecimento esclerosado e mecânico, muito distante do verdadeiro conhecimento
matemático.

De modo geral, a espontaneidade dos alunos de raciocinar matematicamente por vias alternativas, isto é, diferentemente de técnicas e fórmulas, é tolhida diante de um ensino hermético da Matemática que, nos anos iniciais, ainda é normalmente pautado na mecanização do passo a passo dos algoritmos das quatro operações básicas e na aplicação dessas técnicas na resolução de situações-problema. Apesar de as orientações curriculares nacionais, desde os 
Parâmetros Curriculares Nacionais (BRASIL, 1997), há quase duas décadas e meia, apontarem a importância da exploração dos diferentes significados das operações aritméticas básicas e valorizarem as estratégias pessoais de cálculo dos alunos, ainda são recorrentes, nas aulas de Matemática, perguntas como: “que conta eu faço para resolver o problema?” ou “é de mais ou de menos?".

Quanto à ênfase na abordagem dos significados das operações e de outras possibilidades de realizar cálculos, para além da construção da técnica algorítmica, o documento afirma que “com relação às operações, o trabalho a ser realizado se concentrará na compreensão dos diferentes significados de cada uma delas, nas relações existentes entre elas e no estudo reflexivo do cálculo, contemplando diferentes tipos - exato e aproximado, mental e escrito" (BRASIL, 1997, p. 55).

A cultura do ensino das quatro operações aritméticas fundamentais, baseada na apresentação do passo a passo das técnicas algorítmicas, é histórica e estrutural e tem origem em uma concepção de Matemática escolar relacionada à ideia de transmissão dos aspectos formais da área. O algoritmo convencional das operações foi criado a partir das características do nosso sistema de numeração e, em particular, do agrupamento decimal e do valor posicional. Para o professor e o aluno compreenderem o sentido do "vai um" na estrutura algorítmica, é necessário primeiramente que os números a serem adicionados estejam organizados em colunas - valor posicional - e que se entenda que em cada coluna é permitido somente um elemento de um conjunto de nove elementos. De acordo com Mendonça (1996, p. 59), “o conjunto de regras que orienta nossa maneira de escrever os números tem um papel regulador/organizador essencial sobre os passos das técnicas elaboradas para operar com esses números. É absolutamente estreita esta ligação".

Dessa forma, professores e alunos precisam ter domínio sobre o funcionamento do Sistema de Numeração Decimal para atribuir significado às técnicas algorítmicas. Diante da incompreensão desse conhecimento básico e, por meio da mecanização do passo a passo dos algoritmos, professores fazem de conta que ensinam e alunos fazem de conta que aprendem as operações aritméticas fundamentais nos anos iniciais de escolaridade.

É nesse aspecto que Nunes e Bryant (1997) alertam para a importância de numeralizar as crianças. Segundo os autores, a numeralização é processo pelo qual os sujeitos conseguem atuar no mundo, fazendo uso dos conhecimentos matemáticos, percebendo que eles indicam e apoiam a organização de ideias que fazem parte da vida cotidiana. Não se trata, contudo, de descartar a linguagem e sistematizações próprias da matemática, mas de entender que “[...] não se pode confiar em transmitir uma convecção matemática projetada pela cultura - que nesse 
caso é o sistema de numeração. Temos que ter certeza também de que a criança captou os princípios lógicos sobre os quais o sistema se baseia, ou seja, os sentidos que vêm com as convenções" (NUNES; BRYANT, 1997, p. 22).

Pensar matematicamente é compreender em quais situações se torna apropriado manipular os procedimentos matemáticos convencionais ou outros procedimentos, como o cálculo mental exato ou estimativo, e isso só é possível por meio da construção de sentido, ou seja, do entendimento daquilo que se faz nas aulas de Matemática

Considerando que os alunos elaboram conhecimentos matemáticos antes mesmo de frequentarem a escola, uma metodologia para a aprendizagem das operações aritméticas básicas é permitir que estratégias pessoais de realização das técnicas algorítmicas e de resolução de problemas sejam expressas, tanto oralmente, como por meio do registro escrito nãoconvencional. A oportunidade de expressar formas diversas de pensar a Matemática e, consequentemente, de explicitar e argumentar, no coletivo, raciocínios pessoais, revela a compreensão dessa linguagem por parte do aluno e possibilita a negociação de significados entre o que ele e seus colegas já conhecem e o conteúdo a ser sistematizado. Nesse sentido, as discordâncias na resolução das atividades matemáticas, apontadas por Fanizzi (2012), correspondem à possibilidade de ampliação do conhecimento.

\begin{abstract}
No contexto educacional, e mais precisamente no espaço da sala de aula, as discordâncias entre os alunos ou entre alunos e professor são consideradas positivas, pois provocam rearranjos cognitivos, possibilitando, aos participantes da interação, a revisão e a ampliação de conceitos, o que contribui com o processo de ensino e aprendizagem (FANIZZI, 2012, p. 318 e 319).
\end{abstract}

No que tange à resolução do que é denominado por muitos professores, de "continhas", antes de dominar o algoritmo da operação $46+78$ o aluno, pode, por exemplo, atribuir sentido à resolução dessa operação por meio da decomposição, que pode lhe parecer uma estrutura mais familiar: $40+70=110$ e $6+8=14$, portanto $46+78=110+14=124$.

No registro escrito, o uso de algoritmos não convencionais e de representações pictóricas ou esquemáticas consiste em estratégias muito ricas em informações acerca do conhecimento matemático que o aluno já dispõe para resolver situações-problema relacionadas ao cotidiano ou desprovidas de um contexto-ambiente ${ }^{4}$.

Nessa perspectiva, a expressão de como o aluno pensou, antes de classificá-lo como

\footnotetext{
${ }^{4} \mathrm{O}$ uso do termo contexto-ambiente é uma opção das autoras deste artigo para diferenciar os contextos situacionais, geralmente presentes em enunciados de problemas matemáticos, dos contextos intrinsicamente matemáticos, relativos à epistemologia da área de conhecimento. A resolução da operação 34 x 12 pode estar inserida em um contexto-ambiente ou ser proposta em um contexto genuinamente matemático, que instiga o aluno a estabelecer relações e reconhecer regularidades matemáticas.
} 
dotado de dificuldades para aprender Matemática, é fundamental para o professor compreender seu raciocínio. Mesmo que, num primeiro momento, o aluno não apresente oralmente suas estratégias, o registro com o percurso de raciocínio é essencial para a identificação de seu estágio de aprendizagem e compreensão dos conceitos matemáticos.

A partir de um estudo cujo foco foi a análise dos registros de alunos de $3^{\mathrm{a}}$ e $4^{\mathrm{a}}$ séries para a resolução de situações-problema envolvendo as quatro operações fundamentais, Nacarato, Mengali e Passos (2011) apresentam conclusões sobre o tema.

Em síntese, os registros aqui apresentados são ilustrativos de como os alunos criam estratégias diferenciadas para resolver as situações propostas. De um lado, esses registros contribuem para a própria aprendizagem do aluno, pois, ao registrar sua estratégia, ele toma consciência de seus raciocínios e leva em consideração a necessidade de ser o mais claro possível para que o leitor entenda como pensou diante da situação; de outro lado, os registros possibilitam ao professor acompanhar o processo de aprendizagem e evolução do aluno (NACARATO; MENGALI, PASSOS, 2011, p. 62).

É nesse contexto que ideias matemáticas podem ser comunicadas e produzidas pelo aluno que, ao registrar, se coloca em constante reflexão sobre suas ações.

Referindo-se mais especificamente ao desenho, acompanhado ou não de escrita, Cândido (2001, p. 22) afirma que "esses registros servem ao professor como pistas de como cada aluno percebeu o que fez, como ele expressa suas reflexões pessoais e que interferências poderão ser feitas em outras situações para ampliar o conhecimento matemático envolvido em dada atividade".

Na valorização das estratégias pessoais do aluno, o erro deixa de ser punitivo e passa a ser um elemento constitutivo da aprendizagem. É por meio de acertos e erros que os alunos são avaliados desde que a instituição escola existe, seja pelas observações dos professores ou por avaliações externas institucionais. No ensino de Matemática, mais particularmente, o erro sempre esteve diretamente relacionado ao fracasso, pois frente à exatidão do conhecimento matemático cometem-se acertos ou erros. Não há meio-termo. Sem dúvida alguma, se eu tiver 48 brigadeiros e, na minha festa de aniversário, os convidados consumirem 39, certamente sobrarão 9 para eu me deliciar no dia seguinte, porém os caminhos para o aluno chegar a esse resultado podem ser diversos, revelando o que ele já sabe e o que ainda falta saber sobre resolver problemas de adição e de subtração.

O erro assume um novo papel e passa a fazer parte do processo de construção de conhecimento do aluno. Errar o resultado de uma conta, por exemplo, não é mais sinônimo de incapacidade para fazer contas, mas o indicativo, tanto para o professor como para o aluno, dos conhecimentos que ainda faltam ser consolidados. 
Outro aspecto importante de salientar refere-se ao fato de que o professor raramente solicita à criança que ela registre a maneira como pensou para resolver as atividades, o que o impede de interpretar ou deduzir as explicações dos alunos. Deve-se sempre solicitar que o aluno explique como resolveu a atividade, seja de forma oral ou pela escrita. Como afirma Pinto (2000, p.35) “o professor não deverá apenas fazer suposições sobre a lógica dos alunos, mas, para que possa guiar o desenvolvimento de suas ideias, é importante que saiba o que os alunos pensam no momento da aprendizagem".

Sendo assim, o papel do professor é de extrema importância nesse processo de reconhecimento. $\mathrm{O}$ docente pode agir, instigando e propondo reflexões, permitindo que o aluno tenha contato com o seu erro, promovendo discussões tanto entre ele e um aluno, entre os próprios alunos e entre ele e toda a turma, estabelecendo uma dinâmica de aula interativa, de modo que os alunos possam consolidar essa troca de conhecimento e aprender uns com os outros.

Nessa perspectiva, o ensino das quatro operações aritméticas fundamentais necessita, inicialmente, focalizar situações em que os alunos possam interagir, a ponto de construir relações e desenvolver estratégias que lhes pareçam pertinentes, por meio de desenhos, esquemas ou outros percursos pessoais. Nesse processo, eles são conduzidos a desenvolver o raciocínio e a elaborar e organizar registros que subsidiem a construção de significados, para, em seguida, chegar a representações canônicas de resolução como, por exemplo, o uso de algoritmos. Dessa forma, na próxima seção, comentaremos a abordagem que fundamenta este trabalho no que se refere à compreensão dos sentidos das operações aritméticas, mais particularmente, da multiplicação e da divisão.

\subsection{A compreensão dos significados das operações aritméticas fundamentais e a teoria dos campos conceituais}

Até o momento, elaboramos uma problematização teórica sobre o desafio do ensino e da aprendizagem das quatro operações matemáticas, considerando os processos que envolvem o erro, a comunicação e o uso de técnicas canônicas, como os algoritmos convencionais.

Além das reflexões supracitadas, faz-se necessário compreender o que está envolvido na aprendizagem das operações de multiplicação e divisão, uma vez que a proposta deste trabalho foi analisar como alunos, ingressantes no quarto ano, elaboram estratégias de resolução para essas operações.

Nesse sentido, optamos pela teoria dos campos conceituais, idealizada por Vergnaud 
(2014), que aborda a aprendizagem da multiplicação e da divisão como pertencentes ao mesmo campo conceitual, uma vez que, conforme Tarouco (2017, p. 37), "[...] o conjunto de situações que cerca essas duas operações permitem relacioná-las, e, ainda que se considere que cada uma delas possua significação própria, percebe-se, também, a existência de uma complementação [...]”. No caso da multiplicação e da divisão, há um campo conceitual denominado de campo multiplicativo.

Considerando a aprendizagem das operações a partir da perspectiva dos campos conceituais, o tratamento dos conhecimentos matemáticos na escola precisa ser visto como um processo contínuo em que a criança buscará adequar, ampliar ou até mesmo elaborar esquemas novos para construir o conhecimento matemático. Para Pais (2002, p. 61):

\footnotetext{
A formação de um conceito é realizada a partir de componentes anteriores, por meio de uma síntese coordenada pelo sujeito. Esses componentes podem ser noções fundamentais ou ainda outros conceitos elaborados anteriormente, revelando a existência de uma extensa e complexa rede criações precedentes.
}

A ideia de campo conceitual pode ser entendida como um conjunto no qual vários tipos de conceitos se relacionam e oferecem suporte na definição das "regras de ação" utilizadas frente a uma situação que se pretende tratar. Para Vergnaud (2014, p. 312) "a noção de 'regras de ação' [...] deve dar conta do conjunto de comportamentos que se pode observar". É nesse conjunto de comportamentos que se torna possível perceber quais padrões as crianças estão buscando utilizar diante de determinada situação. Vejamos um exemplo concreto de como isso ocorre na Matemática, mais precisamente no campo multiplicativo:

Exemplo 1- Tenho 3 pacotes de canetas. Em cada pacote há 2 canetas. Quantas canetas eu tenho?

Exemplo 2- Ana tem três blusas e duas saias. De quantas formas diferentes ela pode combinar suas roupas?

A solução para ambas as situações se encontra na operação de multiplicação. Entretanto, observa-se que a forma de raciocinar para cada situação, envolve caminhos diferentes. Para Vergnaud (2014), a primeira situação depende de saber colocar em correspondência quatro quantidades, tornando evidente a relação de que um pacote de canetas está para duas canetas, assim como três pacotes de canetas estarão para 6 canetas. Segundo Vergnaud (2014), o exemplo 1 pertence a uma classe específica de problemas, denominada de "Isomorfismo de medidas", na qual relações quaternárias, isto é, entre quatro quantidades, estão implicadas. No segundo exemplo, a situação pressupõe outras maneiras de encontrar estratégias de resolução e, trata-se, para Vergnaud (2014) de pensar sobre três quantidades: quantidade de blusas, de 
saias e o produto entre elas, que forma uma terceira quantidade. Vergnaud (2014) classifica este tipo de problemas como "Produto de medidas" e, ao seu ver, eles envolvem relações ternárias.

Não pretendemos, aqui, identificar todas as classes e subclasses desenvolvidas na teoria dos campos conceituais. Para este trabalho, buscamos, apenas, ressaltar que o ensino e a aprendizagem das operações básicas envolvem uma rede complexa de percepções e ações que o sujeito precisa estabelecer para compreender e operar com os conceitos dessas operações. De maneira geral, Vergnaud (2014) definiu dois grandes campos conceituais na Aritmética: o campo aditivo, referente à adição e subtração, em função da estreita relação entre os processos cognitivos que envolvem essas operações e, o campo multiplicativo, alusivo à multiplicação e divisão.

As reflexões desenvolvidas na teoria dos campos conceituais auxiliam na compreensão dos desafios enfrentados pelas crianças no momento de lidar com as operações aritméticas. Para Vergnaud (2014, p. 312), "Frequentemente os procedimentos utilizados pelas crianças respeitam tão somente uma parte das propriedades das relações em jogo.”. Nesse sentido, é importante avaliar com cuidado os procedimentos utilizados pelos alunos, afim de entender o raciocínio utilizado por eles.

No segundo tópico do referencial teórico, buscamos sintetizar as ideias nas quais nos apoiamos para compreender o processo de significação das operações do ponto de vista da criança, de modo que o leitor possa acompanhar as interpretações realizadas ao longo da análise dos dados coletados para este estudo.

\section{METODOLOGIA}

Considerando que este trabalho visou descrever e analisar os registros de alunos, inseridos no contexto da avaliação diagnóstica da escola participante da pesquisa, optamos pela metodologia qualitativa de abordagem interpretativa. A partir dessa perspectiva metodológica mais geral, utilizamos o método de análise de conteúdo para fazer inferências sobre os registros das crianças que "desenvolve-se em três fases: (a) pré-análise; (b) exploração do material; e (c) tratamento dos dados, inferência e interpretação" (Bardin, 1977, p. 95 apud GIL, 2008, p. 152).

Inicialmente, tivemos contato com a avaliação diagnóstica de todos os alunos do $4^{\circ}$ ano. O instrumento contava com 20 questões, sendo 18 delas de múltipla escolha, uma de completar, na qual o aluno deveria indicar o instrumento de medida correto ao contexto das frases apresentadas, e uma de resolução de cálculos de multiplicação e de divisão, em que constava espaço para registro. O critério para optarmos pela análise da questão envolvendo as operações 
de multiplicação e de divisão - a questão 11 - corresponde ao fato dessa questão ser a única com possibilidade de registro pelas crianças, sendo, dessa forma, viável a realização de reflexões sobre os aspectos que permeiam os processos desenvolvidos pelos alunos.

Inicialmente, identificamos quatro tipos de manifestações dos alunos e organizamos a provas nesse sentido: no primeiro tipo, a questão é deixada em branco e, nesse caso não há indício sobre como o aluno raciocina. Ainda assim, a constatação de respostas em branco é válida para a construção do mapeamento dos alunos que precisam do apoio pedagógico. $\mathrm{O}$ segundo tipo de manifestação corresponde ao das respostas sem demonstração de estratégias vale lembrar que, apesar de haver espaço para a produção de registros, a questão não exige que os alunos os façam. Nessa segunda manifestação, é possível identificar respostas corretas e incorretas; tais respostas também são importantes para o mapeamento das turmas. O terceiro tipo de manifestação foi por meio de esquemas, desenhos ou outras estratégias, o que nos possibilitou uma análise mais detalhada do pensamento do aluno. E, por fim, no quarto tipo de manifestação, algoritmos convencionais são apresentados pelos alunos, nos quais se percebem erros e acertos.

A análise dos dados focalizará os dois últimos tipos de manifestação, que nos permitiram compreender os percursos adotados pelos alunos e inferir possíveis raciocínios que eles utilizam na resolução de multiplicações e divisões. Dessa forma, criamos duas categorias de análise: 1) registro por meio de estratégias não convencionais e 2) registro por meio de algoritmos. A partir dessas duas categorias, buscaremos interpretar os caminhos adotados pelas crianças.

\section{RESULTADOS E ANÁLISES}

\subsection{Registro por meio de estratégias não convencionais}

Iniciaremos a análise dessa categoria com a observação de estratégias cujo resultado foi correto, para em seguida tecer elucidações que nos ajudem a interpretar o que está em jogo em manifestações espontâneas. Observemos as imagens que ilustram as estratégias do aluno A para multiplicação e do aluno B para divisão: 


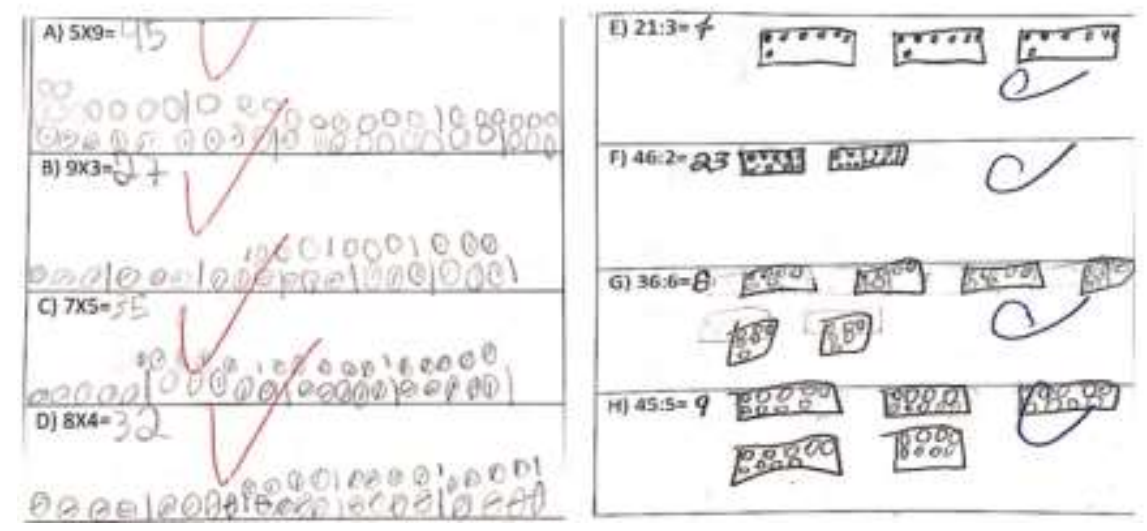

Figura 2: percurso na multiplicação do aluno A e percurso na divisão do aluno B. Fonte: Registro selecionado pelas pesquisadoras a partir da coleta de dados.

Observa-se que, na multiplicação, o aluno A compreende a função do multiplicador e do multiplicando. Na primeira operação, ele replica o número nove cinco vezes para chegar ao resultado e ele utiliza a mesma estratégia nas outras operações, sempre mantendo a função do multiplicador e multiplicando. Aqui, é possível fazer duas inferências: $1^{\circ}$ ) o aluno sabe multiplicar, mas não domina a tabuada, pois precisou do desenho para chegar à resposta e, $2^{\circ}$ ) ele sabe a tabuada e optou por um registro de esquemas para conferir a resposta e, ao mesmo tempo, apresentar, ao professor, uma solução, dado o fato que havia um espaço para resolução. Independentemente dessas duas inferências, se trata de um aluno que consegue realizar operações de multiplicação, oferecendo sentido aos fatores da operação.

O percurso realizado pelo aluno B nas operações de divisão é semelhante ao que ocorreu com o aluno A. Na estratégia utilizada, ele pressupõe que o divisor representa a quantidade de repartições que devem ser feitas, logo, na primeira conta, distribui 21 elementos entre três grupos, encontrando o resultado correto. Mas, ainda nos resta a pergunta: como ele chegou à conclusão de que deveriam ser sete elementos dentro de cada grupo?

Algumas inferências, sobre esse aspecto, são: $1^{\text {a }}$ ) pode ter feito uma distribuição termo a termo, dentro de cada grupo e, $2^{\mathrm{a}}$ ) pode ter utilizado a tabuada como recurso. Assim, como no caso anterior, o aluno demonstra que consegue realizar operações de divisão, atribuindo sentido à função do dividendo e divisor.

Agora analisemos uma situação em que outro aluno tenta realizar o mesmo procedimento nas contas de divisão, porém não obtém sucesso: 


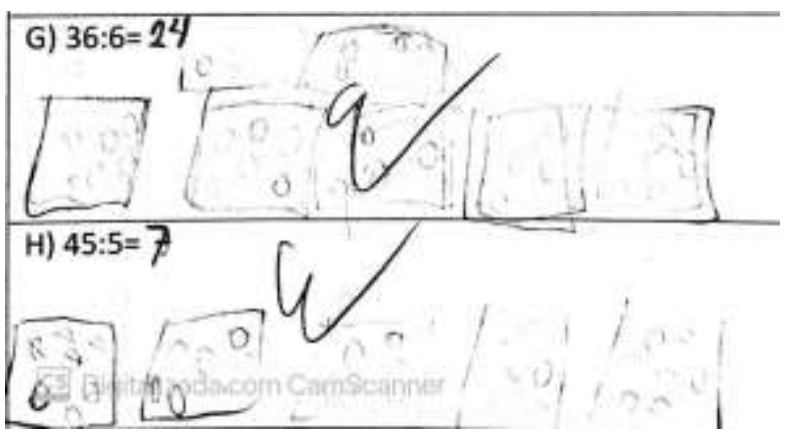

Figura 3: tentativa do uso do desenho na divisão, aluno C.

Fonte: Registro selecionado pelas pesquisadoras a partir da coleta de dados.

Observa-se que o aluno $\mathrm{C}$ também tenta criar a possibilidade de grupos, porém não chega a uma conclusão, o que pode ocorrer pela falta de uma referência que ofereça indicações sobre o significado do divisor. Nota-se que a resposta que ele oferece para a questão $36: 6(24)$ não traduz uma aproximação com sua tentativa de resposta. Pode-se inferir que ele não consegue estimar, o que também indica que não entende o significado da própria operação, pois não conseguiu interpretar a função dos números nessa situação.

É interessante refletir que, tanto na multiplicação como na divisão, o que está em jogo é um pensamento de ordem mais complexa, que exige do aluno um raciocínio elaborado sobre o sentido da operação. Se estabelecermos comparação com o raciocínio aditivo, perceberemos que, na adição, o pensamento "está centrado sobre os objetos que se reúnem a outros [...] e a multiplicação, na qual se trata, ademais, de depreender o número de vezes que se reúnem e de desmembrar, então as operações como tais, e não mais somente seus resultados enquanto número de objetos transferidos. " (PIAGET, 1995, p. 31)

Nos casos analisados podemos inferir que é necessário centrar o pensamento no mecanismo que representa a ação de replicar ou repartir e, com isso, exige-se a identificação de um operador sem dimensão $0^{5}$, que não indica um elemento específico como normalmente ocorre em operações do campo aditivo. Ao tratar da adição e da subtração, as crianças se habituam a olhar para os números como a representação de quantidades de elementos. No campo multiplicativo, nem sempre os números apresentarão o papel de elementos, mas indicarão como os elementos se coordenam em relação uns aos outros e é nessas relações que o pensamento precisa se deter.

\footnotetext{
${ }^{5}$ Vergnaud (2014, p. 241) define como operador escalar a ideia de um operador sem dimensão, isto é, que não representa uma medida. Como exemplo, ele utiliza situações do tipo: "Paguei R\$ 12,00 por 3 garrafas de vinho. Quanto custa cada garrafa?", verifica-se, nestes casos, que o operador $\div 3$ se trata de um operador que não representa as garrafas e nem o valor em dinheiro, mas sim a quantidade de repartições que deve se fazer do valor em dinheiro.
} 
Como foi indicado acima, o aluno B já consegue entender que o divisor seis pode indicar o número de repartições e que o 36 representa elementos a serem distribuídos em cada uma das repartições, nesse caso a quantidade distribuída dentro de cada repartição se torna o quociente, ou seja, a resposta é o número de elementos dentro de cada grupo.

O que há de mais relevante na manifestação do aluno C?

O aluno apresenta a tentativa de um caminho, mas entra em conflito, provavelmente por não conseguir coordenar a relação existente entre os números. Isso demandaria a compreensão do papel dos termos da operação, compreensão que o aluno B demonstra ter. Mas não é fácil chegar a essa construção, uma vez que dividir engloba formas variadas de pensar. No caso de não saber como realizar a distribuição entre os elementos, nos grupos definidos pelo divisor (aparentemente o que aconteceu com aluno C), seria possível fazer do divisor uma cota mínima para saber quantas vezes ele cabe no dividendo. Usemos como exemplo a letra $\mathrm{H}$ do exercício: $45 \div 5$, ao invés de definir 5 grupos como fez o aluno B, poderíamos verificar quantas vezes o cinco cabe no 45 , o que se aproxima da tentativa do aluno $C$ e nos conduz ao seguinte esquema:

\begin{tabular}{ll|l|l|l|l|}
\hline 00000 & 00000 & 00000 & 00000 & 00000 & 00000 \\
00000 & 00000 & 00000
\end{tabular}

Figura 4: simulação do registro pelo desenho na divisão. Fonte: das autoras.

Nesse caso, o quociente é dado pelo número de grupos e não pelo número de elementos dentro do grupo, como fez o aluno B. Com isso, fica evidente que dividir pressupõe mais de um caminho, entretanto, cada caminho implica uma interpretação diferente acerca da relação entre os números envolvidos na operação. Por isso, nos parece conveniente uma análise mais aprofundada da própria atividade, de modo que o aluno explique sua estratégia oralmente, o que será realizado em momento posterior, em um contexto que possibilite a ele se expressar.

Como foi dito anteriormente, a atividade pressupõe que o aluno já domine os sentidos que a divisão possa ter. É interessante notar a necessidade que outro aluno sentiu de criar uma situação para resolver a divisão. Notemos as estratégias do aluno D:

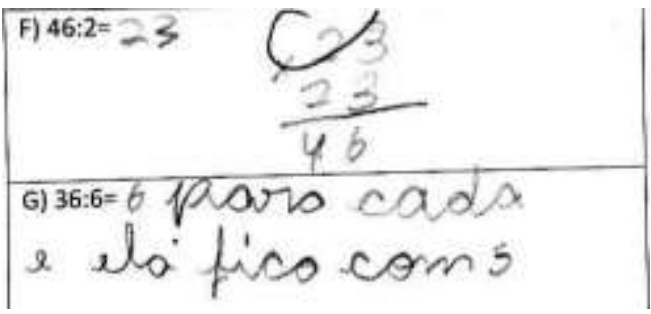

Figura 5: registro do aluno D.

Fonte: Registro selecionado pelas pesquisadoras a partir da coleta de dados. 
Na questão G, ele responde com a criação de uma situação. Não é possível interpretar como o aluno pensou, mas fica evidente que ele sentiu a necessidade de um contexto para saber como relacionar os números envolvidos na operação. Ao manifestar a frase "6 para cada e ela fica com 5" o aluno parece ter tentado criar uma estratégia que o ajudasse a compreender a função dos números ou de se aproximar de uma estratégia canônica de resolução de problemas que envolvam divisão. Nota-se, ainda, que na questão F, ele se utiliza da ideia de metade para chegar à resposta e, utiliza o algoritmo da adição para conferir se sua divisão está correta ou para apresentar uma estratégia de resolução no espaço que parecia existir para essa finalidade. Dividir por dois implica sempre na noção de dividir algo ao meio, e, nesse caso, de aplicar um raciocínio que facilita a interpretação dos termos da operação.

Apesar de o aluno D não se enquadrar no eixo "estratégias não convencionais", consideramos pertinente a análise e apresentação de seu percurso nesse momento, justamente por indicar a necessidade de um contexto. Ora, a divisão está implicada em um conjunto de situações em que cada situação pode revelar um modo muito específico de pensar como os números se relacionam.

Nossas análises nos conduzem à reflexão de que na sala de apoio pedagógico seja necessária a construção de propostas que permitam os alunos perceberem que o campo multiplicativo envolve uma reflexão para além dos números como representação da quantidade de elementos, isto é, também como indicação da relação existente entre os elementos envolvidos. Dessa forma, torna-se necessário desenvolver propostas de atividades que os façam perceber essas ações a partir de um contexto, para que eles possam coordenar os números envolvidos na operação e, oferecer sentido a elas. Somente depois de se apropriar do sentido das operações é que os alunos poderiam realizar com segurança a atividade proposta na avaliação. Essa segurança foi manifestada pelo aluno A, no caso da multiplicação e, pelo aluno B, no caso da divisão, pois ambos acertaram todas as contas e demonstraram os percursos adotados com clareza.

A seguir apresentaremos nossa interpretação das respostas que buscaram apoio nos algoritmos para realizar a atividade.

\subsection{Registro por meio de algoritmos}

Para esta categoria não apresentaremos casos de acertos, pois o uso do algoritmo pressupõe um domínio de técnicas que os alunos podem controlar, sem necessariamente manifestar como compreendem a operação. Por esse motivo, julgamos que para quem acertou 
o algoritmo, existem apenas duas inferências: $1^{\text {a }}$ ) compreende a operação e domina as regras do algoritmo, ou $2^{\mathrm{a}}$ ) apenas domina as regras do algoritmo.

Os registros com "erros", por sua vez, nos interessam por permitirem reflexões sobre as tentativas de compreensão que os alunos elaboram sobre o conhecimento matemático das operações. Vejamos alguns registros:
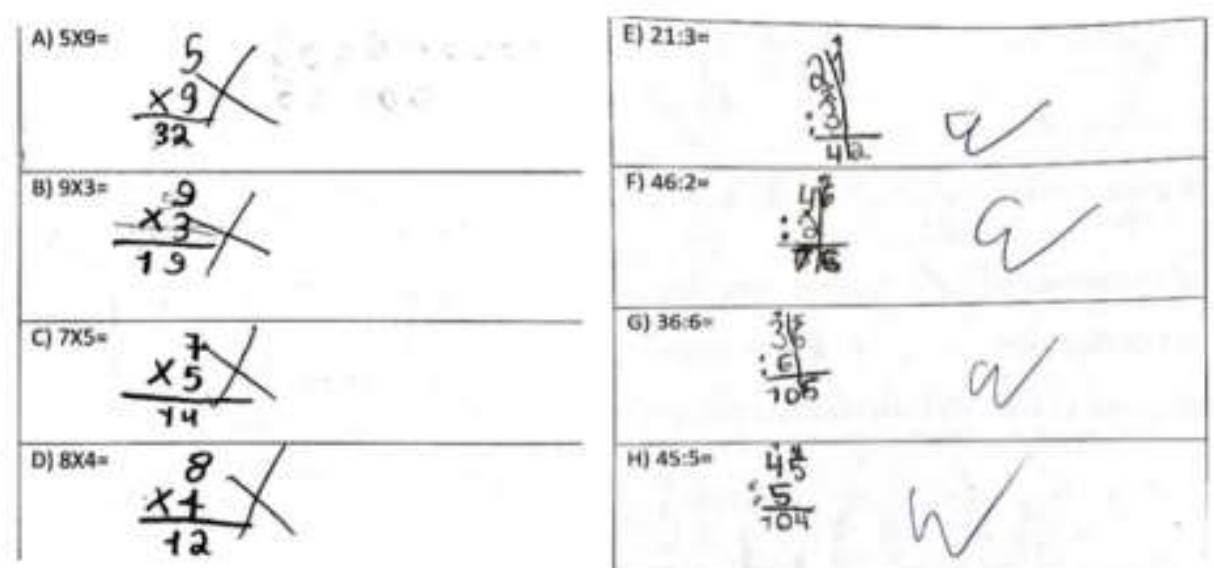

Figura 6: percurso na multiplicação do aluno E e percurso na divisão do aluno F. Fonte: Registro selecionado pelas pesquisadoras a partir da coleta de dados.

Iniciemos pelo caso da multiplicação realizada pelo aluno E, em que armar a conta não conduz ao acerto. Aqui é necessária uma reflexão sobre a função do algoritmo na Matemática escolar, como foi apontado na fundamentação teórica deste artigo. A produção de significados sobre as técnicas algorítmicas só é possível quando há dinâmicas de comunicação e interação na sala de aula, quando o aluno pode desvelar e justificar os procedimentos envolvidos na técnica. Para Nunes e Bryant (1997), é a partir desse momento que ele pode fazer o uso da técnica algorítmica como ferramenta de seu pensamento, principalmente quando estratégias pessoais se tornam pouco práticas na resolução de problemas. Mas quando isso ocorre?

Os algoritmos convencionais favorecem o trabalho com números altos, pois, nesses casos, não é mais pertinente desenhar ou fazer esquemas que representem as quantidades envolvidas. No ensino dos algoritmos, caberia ao professor articular as estratégias canônicas, apoiadas na linguagem matemática, de forma articulada às estratégias pessoais. É interessante notar que nas operações da avaliação diagnóstica, apresentá-las na horizontal ou na vertical não acarreta diferença no momento de buscar uma solução. Mesmo assim, o aluno E optou por organizar a conta na vertical, o que provavelmente indica o entendimento de que, armando a conta, surgem pistas sobre como encontrar o resultado. No entanto, o resultado depende mais da coordenação das ideias envolvidas na operação do que da construção do algoritmo, que tem valor somente quando o conceito da operação já está internalizado, ou seja, quando o sujeito é 
capaz de dominar as relações existentes entre número, sistema de numeração decimal e significados da operação, envolvidas nos procedimentos de cálculo.

Nota-se que o aluno F também optou por procedimentos convencionais de cálculo, possivelmente apoiado na crença - assim como o aluno E - de que a Matemática escolar pode ser manifestada unicamente por meio de representações envolvendo números e algoritmos. $\mathrm{O}$ registro do aluno F não representa o algoritmo usual da divisão; é provável que o mesmo ainda não lhe tivesse sido apresentado, pois ele tenta adotar procedimentos utilizados nos algoritmos da adição, da subtração e da multiplicação. O aluno posiciona os numerais um abaixo do outro, indicando o sinal da operação à esquerda, e registra um traço vertical entre os algarismos do numeral, recurso utilizado para indicar o valor posicional quando se arma contas. Apesar de sua tentativa, o aluno F não obtém sucesso.

Considerando esses dois exemplos, verificamos que qualquer estratégia adotada na resolução das operações, mesmo que apoiada na construção de algoritmos convencionais, precisa se revestir de sentido; não basta decorar o passo a passo das técnicas algorítmicas para sempre se obter sucesso.

\section{CONSIDERAÇÕES FINAIS}

O objetivo desse estudo foi identificar quais possibilidades de resolução para as operações de multiplicação e divisão os alunos que se encontram no início do $4^{\circ}$ ano desenvolvem. A partir das análises das avaliações diagnósticas, enfatizamos, inicialmente, a importância de o professor compreender como os alunos pensam para resolver as atividades, valorizando os diferentes registros e a possibilidade de comunicação de cada aluno para entender os processos por ele realizados e identificar suas demandas frente à aprendizagem das operações.

Nossas análises indicaram a complexidade envolvida no processo de compreensão da multiplicação e da divisão. Ao tentarem resolver essas operações, as crianças revelaram percursos ora relacionados a conhecimentos anteriores, como foi o caso do aluno D, que aproveitou o conceito de metade para resolver uma das questões de divisão - conforme apresentado no tópico 4.1, ora referentes a percursos que indicaram que as crianças mantiveram seu pensamento centrado em formatos postulados pela escola, tentando reproduzir o uso de algoritmos como forma de solucionar as operações, como foi o caso do aluno $\mathrm{F}$-conforme apresentado no tópico 4.2 . 
Dessa forma, desvelar os registros elaborados pelos alunos é fundamental nos processos de ensinar e de aprender Matemática. Como foi verificado, há registros que contêm erros e que, muitas vezes, revelam tentativas de acerto providas de sentido matemático. Nesse caso, cabe ao professor identificar o que o aluno já sabe para, a partir de suas manifestações, planejar intervenções que promovam o seu desenvolvimento. Em outras situações, o erro pode ser fruto de resoluções mecanizadas, desprovidas de significado, o que denota a crença do aluno (e possivelmente também do professor) de que para saber Matemática é suficiente realizar o passo a passo das técnicas e conhecer "regrinhas". Em ambos os casos, torna-se necessário, ao professor, reconhecer que o erro não pode ser desprezado, merecendo o devido tratamento.

A aprendizagem decorre da negociação de significados entre o que o aluno já sabe e o que lhe é proposto que aprenda e a negociação de significados somente é possível a partir da expressão das formas de pensar e resolver as atividades matemáticas. Dessa forma, realizar listas e mais listas de contas, com uma devolutiva do professor baseada na classificação certo (com a marca $\mathrm{C}$ ) e errado (com a marca $\mathrm{X}$ ) nunca conduziu e jamais conduzirá o aluno à aprendizagem das quatro operações fundamentais. Torna-se fundamental, portanto, uma ressignificação do ensino de Matemática e, consequentemente, mudanças na prática docente de professores que ainda creem nessa concepção de ensinar Matemática.

\section{REFERÊNCIAS}

BRASIL. Ministério da Educação. Secretaria da Educação Básica. Base Nacional Comum Curricular: educação é a base. Brasília, DF, 2017. Disponível em:

<http://basenacionalcomum.mec.gov.br/abase/ >. Acesso em: 02 ago. 2020.

BRASIL. Secretaria de Educação Fundamental. Parâmetros Curriculares Nacionais: introdução aos parâmetros curriculares nacionais / Secretaria de Educação Fundamental. Brasília: MEC/SEF, 1997. Disponível em:

<http://portal.mec.gov.br/seb/arquivos/pdf/livro01.pdf>. Acesso em: 14 jul. 2020.

CANDIDO, P. T. Comunicação em Matemática. In: DINIZ, M. I.; SMOLE, K. S. (Org.). Ler, escrever e resolver problemas: Habilidades básicas para aprender matemática. Porto Alegre: Artmed, 2001.

FANIZZI, S. A Importância da Comunicação e da Interação nas Aulas de Matemática: da elaboração oral à construção de conhecimentos. Educação Matemática Pesquisa: Revista do Programa de Estudos Pós-Graduados em Educação Matemática, [S.1.], v. 14, n. 2, p. 317-336, set. 2012. ISSN 1983-3156. Disponível em: <https://revistas.pucsp.br/emp/article/view/9443 >. Acesso em: 14 jul. 2020.

GIL, A. C. Métodos e técnicas de pesquisa social. - 6. ed. - São Paulo: Atlas, 2008. 
GOMEZ-GRANELL, C. Rumo a uma epistemologia do conhecimento escolar: o caso da educação matemática. In: RODRIGO, M.J.; ARNAY, J. (orgs.). Domínios do conhecimento, prática educativa e formação de professores. v. 2. São Paulo: Editora Ática, 1997. p. 15- 41.

MENDONÇA, M. do C. D. A intensidade dos algoritmos nas séries iniciais: uma imposição sócio-histórico-estrutural ou opção valiosa? Zetetike, v. 4, n. 5, p.55-76, jan/jun. 1996. ISSN 2176-1744. Disponível em:

〈https://periodicos.sbu.unicamp.br/ojs/index.php/zetetike/article/view/8646864/13765>.

Acesso em: 02 ago. 2020.

NACARATO, A. M.; MENGALI, B. L. S.; PASSOS, C. L. B. A matemática nos anos iniciais do ensino fundamental: tecendo fios do ensinar e do aprender. Belo Horizonte: Autêntica, 2011.

NUNES, T; BRYANT, P. Crianças fazendo matemática. Porto Alegre: Artes Médicas, 1997.

PAIS, L.C. Didática da Matemática: uma análise da influência francesa - 2. ed - Belo Horizonte: Autêntica, 2002.

PIAGET, J. Abstração reflexionante: relações lógico-aritméticas e ordem das relações espaciais. Porto Alegre. Artes Médicas, 1995.

PINTO, N. B. O erro com estratégia didática: Estudo do erro no ensino da matemática elementar. Campinas, SP: Papirus, 2000.

PONTE, J. P.; SERRAZINA, M. L. Didáctica da matemática do $\mathbf{1}^{\mathbf{0}}$ ciclo. Universidade Aberta, 2000. Capítulo 6: Dinâmica do processo de ensino, p. 109-130.

TAROUCO, V.L. Ensino da divisão no primeiro ciclo do ensino fundamental: análise das práticas pedagógicas de professores. Dissertação (Mestrado em Educação) - Programa de pósgraduação em Educação, Instituto de Educação, Universidade Federal de Mato Grosso.

Cuiabá, p. 120. 2017.

VERGNAUD, G. A criança, a matemática e a realidade: problemas do ensino da matemática na escola elementar. Curitiba: Ed da UFPR, 2014.

Submetido em: 11 de setembro de 2020 .

Aprovado em: 30 de novembro de 2020. 